\title{
Assessing Sustainability of Organic Livestock Farming in Sicily: A Case Study Using the FAO SAFA Framework
}

\author{
Mariarita Cammarata, Giuseppe Timpanaro* ${ }^{*}$ and Alessandro Scuderi \\ Department of Agriculture, Food and Environment (Di3A), University of Catania, 95123 Catania, Italy; \\ mariar.cammarata@gmail.com (M.C.); alessandro.scuderi@unict.it (A.S.) \\ * Correspondence: giuseppe.timpanaro@unict.it
}

Citation: Cammarata, M.

Timpanaro, G.; Scuderi, A. Assessing Sustainability of Organic Livestock Farming in Sicily: A Case Study Using the FAO SAFA Framework. Agriculture 2021, 11, 274. https:// doi.org/10.3390/agriculture11030274

Academic Editors: Sanzidur Rahman and Les Copeland

Received: 1 February 2021

Accepted: 18 March 2021

Published: 23 March 2021

Publisher's Note: MDPI stays neutral with regard to jurisdictional claims in published maps and institutional affiliations.

Copyright: (c) 2021 by the authors. Licensee MDPI, Basel, Switzerland. This article is an open access article distributed under the terms and conditions of the Creative Commons Attribution (CC BY) license (https:// creativecommons.org/licenses/by/ $4.0 /)$.

\begin{abstract}
Greenhouse gas (GHG) emissions and pollutants, soil erosion and groundwater pollution are some of the negative aspects blamed on livestock farming, so their level of sustainability needs to be assessed, taking into account the territory in which they operate. The research focuses on the assessment of sustainability performance in the four dimensions of good governance: environmental integrity, economic resilience and social well-being, considered by the "Sustainability Assessment of Food and Agriculture Systems" (SAFA) tool developed by Food and Agriculture Organization (FAO). The objective of applying this methodology is to highlight the sustainability dimensions in which the ten analyzed farms are weakest and the ones in which they show the most strength, in order to provide farmers a tool to understand the criticalities on which to intervene. The farms considered follow the principles of agroecology and organic farming, which are decisive in the pursuit of sustainable development. The overall results show a satisfactory level of sustainability with high prospects for improvement, in line with the EU commitments undertaken in the Green Deal and the Millennium Development Goals. Livestock farms must, therefore, be encouraged and accompanied with targeted technical assistance strategies and appropriate agroecological protocols.
\end{abstract}

Keywords: agroecology; animal husbandry; sustainable development; policy; environment; economics; social

\section{Introduction}

The urgency of starting a process of environmental regeneration as a result of the pressure exerted by human activities on the Earth's resources prompted in 2015 the Member States of the United Nations to draw up the Sustainable Development Goals (SDG), valid until 2030, in order to provide a shared program of peace and prosperity for the people and planet, for the present and the future [1]. The sustainable development can be intended as proposals based on environmental, social and economic sustainability. Lewandowski et al. [2] defined sustainable agriculture as the "management and utilization of the agricultural ecosystem in a way that maintains its biological diversity, productivity, regeneration capacity, vitality, and ability to function, so that it can fulfill, today and in the future, significant ecological, economic and social functions at the local, national and global levels and does not harm other ecosystems". Sustainability is linked to resilience: a complex ecosystem is characterized by a high degree of diversity and resists disturbances without significant structural and functional changes [3]. Agroecology is considered the scientific basis of sustainable agriculture, as it integrates traditional knowledge with modern knowledge to obtain production methods that respect environment and society, in order to achieve not only production goals, but also the social equality and ecological sustainability of the agroecosystem [4]. We consider agroecology in its normative sense, including its socio-economical, cultural, and political dimensions [4-6]. The Food and Agriculture Organization of the United Nations (FAO) published a document proposing the ten elements of agroecology [7] in which the common characteristics of agroecological systems are defined and key considerations in enabling the environment to accommodate agroecology are given. 
The purpose of this document is to guide countries to transform their food and agricultural systems, placing agroecology in a framework that may help policymakers, practitioners and stakeholders in planning, managing and evaluating agroecological transitions. The ten elements are diversity, the co-creation and sharing of knowledge, synergies, efficiency, recycling, resilience, human and social values, culture and food traditions, responsible governance and circular and solidarity economy [7].

Within the agri-food chain, this paper focuses on the livestock sector. The growth of the world's population and pressure from climate change has sparked debate about the impacts generated by livestock sector [8]. However, before assessing its impact, it is necessary to consider that this sector differs widely in terms of production targets, degree of intensification, environmental context and cultural role, among other characteristics [8]. The traditional livestock systems are largely based on the use of meadows and pastures and produce not only food and fiber but also other fundamental services for society, such as conservation of genetic resources, water flow regulation, pollination, climate regulation, landscape maintenance, recreation and ecotourism and cultural heritage [9-11]. The many benefits associated with animal husbandry make it necessary to measure the sustainability level of this sector. According to the 'triple bottom line' of sustainability, the concept of sustainable development traditionally included environmental, social and economic dimensions [12]. The United Nations Commission on Sustainable Development (CSD) formally introduced governance as the fourth dimension [13]. Sustainability assessment has been viewed as "a tool that can help decision-makers to decide what actions they should take and should not take in an attempt to make society more sustainable" [14]. Assessing the sustainability and efficiency of an agroecosystem requires the use of indicators capable of providing information about it in an objective and easily interpretable manner. They make perceivable a phenomenon that is not immediately and easily detectable, and allow us to understand the sustainability status of an agroecosystem or the critical aspects that endanger it [15]. There are different methods and tools capable to assess the sustainability level of farms such as "Sustainability Assessment of Food and Agriculture Systems" (SAFA) [16], "The Response-Inducing Sustainability Evaluation" (RISE) [17], and "The Committee on Sustainability Assessment Tool" (COSA) [18]. The three frameworks have a global geographic applicability, but differ in terms of sector applicability, sustainability perspective and targeted stakeholders $[19,20]$. The research is based on the sustainability assessment of organic livestock farming in the mountain areas of central Sicily through the use of Sustainability Assessment of Food and Agriculture systems (SAFA) [16] indicators developed by the Food and Agriculture Organization of the United Nations. The role of organic agriculture in developing local economies and increasing per capita income, improving the quality of life for entire areas and creating local markets for sustainable agricultural products is internationally recognized [21]. A knowledge of these production systems and the sharing of know-how from these farmers thus enables the development of innovative approaches to sustainable development and food security that is more bio-diverse, resilient and socially fair [21]. The reference area is particularly suited to organic cattle farming so, using SAFA indicators, the aim is to highlight the strengths and weaknesses of the sector in order to suggest to farmers a holistic approach in managing their farms.

\section{Materials and Methods}

\subsection{The Importance of Agroecology and Its Connection with the SAFA Tool}

In order to combat food deprivation and world hunger, the green revolution started a process of introducing new technologies into agriculture that began in the 1940s and spread in the 1960s and 1970s [22]. It led to numerous disadvantages and negative aspects, including increased environmental impact, loss of biodiversity, erosion of genetic resources and socio-economic decline affecting smallholders that could not afford the expense of new technologies to increase their production. The solution to the above has been offered by agroecology [23]. This term was first used by the Russian agronomist Basil Bensin in 1928 to refer to the combination of ecology and agriculture; thus, it was defined as a 
science related to other disciplines, such as zoology or plant physiology [23]. Over the decades, agroecology was not only considered a scientific discipline, but its principles were incorporated into public policy and global agencies. Production in agroecological farming systems (AFSs) does not rely on intensive use of external inputs. Rather, it is based on an integrated and holistic social-ecological approach, utilizing local resources and socially accepted and culturally adapted technologies, while maximizing the ecosystem service provision [24-28]. A wide variety of agroecological practices that improve agricultural production at no charge to the environment or biodiversity have existed for decades [29]. Agroecological practices are mostly applied by farmers involved in integrated agriculture or organic farming. In most highly industrialized countries with large-scale farming and animal husbandry systems, the use of agroecological practices is still limited. In contrast, in less intensive systems, e.g., in hilly or mountain less favored areas, different agroecological practices have been more widely applied as these areas have less potential for intensive production [29]. These practices are essentially based on the diversification concept. This is achieved, for example, with the integration of cultivars, crops, or intercrops, the use of agroforestry systems, and the enhancement of semi-natural landscape elements [29]. The overall objective is to improve various ecosystem services linked to diversification in order to increase the resilience of agroecosystems to disturbance, to decrease pest outbreaks or control them to an acceptable level, and to conserve agrobiodiversity. The application of agroecological practices, however, requires the redesign of production systems, which during the green revolution were simplified to maximize yields and profits [30]. In order to assess the sustainability of farms, SAFA is designed for global application, unlike the others it does not only consider three dimensions of sustainability but introduces the policy or governance dimension. This tool also involves the farmer as an active part of the sustainability measurement process, i.e., as a beneficiary of the improvements that can be made and not as a mere stakeholder in the production process [31]. Based on insights from agroecology and political ecology, this focus on farmers would benefit from considering the reasons why agriculture is unsustainable [32]. Agroecologists commonly apply a systemic focus to agriculture where the interactions between different factors are central to the analysis. The importance of combining environmental aspects with social and ecological ones makes SAFA an integrated tool capable of placing farming in their environmental and social context. SAFA is based on the assumption that a lack of common language on agricultural sustainability and a lack of knowledge among farmers (and in the food chain) on the impacts from agriculture impede changes in agricultural practices [33].

\subsection{The Livestock Sector in the Sicilian Mountain Areas}

The livestock sector in European mountain areas is very diversified. Geographical and climatic traits represent limits for feed production, traditionally based on fodder and pastures $[34,35]$. In the mountain areas of Central Sicily the agricultural sector and particularly the livestock one represent the main activity of the rural areas (Figure 1).

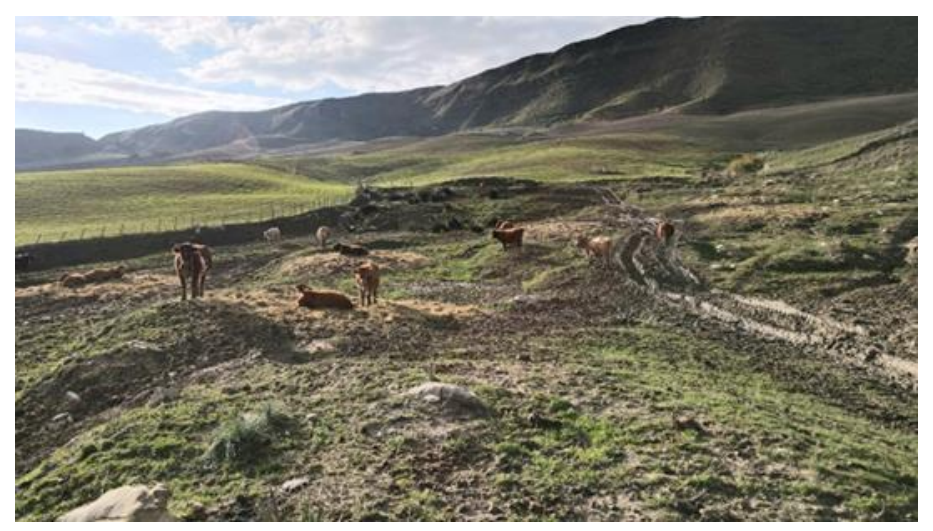

Figure 1. Cattle farm in the mountain areas of central Sicily. 
As reported in Sinab data [36], Italy has an organic surface of 1,993,236 hectares. The three main production orientations that weigh on the total for more than $60 \%$ are: Pasture Meadows (551,074 ha), Fodder Crops (396,748 ha) and Cereals (330,284 ha). In 2019, the organic surface area in Sicily amounted to 370,622 hectares, placing it among the regions with the largest share of operators, which amounted to 10,596 units. The average size of farms in southern Italy is 24.6 ha [36]. Regarding livestock farms and more specifically those characterized by cattle, it is possible to state that in Italy the number of heads at 31 December 2019 of organic livestock farming is limited to $4 \%$ for cattle, which demonstrates the urgent need to support the sector by improving its potential [36].

The issues influencing the sustainability of mountain farming systems are numerous and closely interconnected [37]. At the farm level, technical and social aspects should be considered in relation to environmental impacts, as the socio-economic context. With the introduction of technology, intensive farms have gradually replaced traditional farms, with the aim of increasing production per head and per farm income, but have also increased the problems, the abandonment of marginal lands and loss of biodiversity [38-40]. The latter as a consequence of abandoning traditional farming practices is linked to the degradation of pastures and forest re-growth. The important role of livestock farming in mountain areas in the prevention of fire [41], soil erosion and greenhouse gas (GHG) emissions [42] should also not be overlooked. The problem of GHG emissions should be considered separately due to the possible mitigating effect of the carbon sequestration of meadows and pastures [8]. In addition to the above self-sufficiency of fodder imposes limits on loaded livestock, thus avoiding excessive manure production and a consequent risk of eutrophication. this limits the abandonment of marginal areas and as regards the product quality it strengthens the link between the territory and the identity of the products [8]. From a social viewpoint, the average age of farmers and the intergenerational succession are relevant. It is well known that the average age of farmers in mountains is constantly increasing [43,44], and the generational turnover is poor due to the low interest of young people in farming [45]. For livestock farming to be considered sustainable, attention must be paid to animal welfare. In the mountain areas of Sicily, livestock are mainly left to graze and only stabled at night or on cold winter days. Although mountain livestock farming is considered to be respectful of animal welfare by European citizens, it can often result in restrictive conditions, such as tie-stalls [8].

The aim of farmers who decide to adopt an organic farming system is to reduce environmental impacts while obtaining a good economic result but above all to provide the consumer with a sustainable, quality product [46]. The livestock sector in Sicily, especially in mountain areas, is characterized by a lower number of adult cows than the permitted norm. In addition to the production purpose they perform the function of landscape conservation, protection from fires and the possibility of using marginal areas otherwise uncultivated.

\subsection{Sustainability Assessment of Food and Agriculture Systems (SAFA)}

The sustainability assessment of Sicilian livestock farming was carried out using the SAFA methodology. It is peculiar for its wide range of sustainability dimensions, its global applicability to both large and small farms, and its ease of applicability. SAFA, which focuses mainly on agri-food and rural systems, was developed by the FAO (Food and Agriculture Organization of the United Nations) in 2012 with the aim of evaluating the degree of sustainability of agricultural holdings and providing private and public entities with a set of indicators that are useful for detecting issues and identifying solutions. The chosen methodology is characterized by a holistic approach to sustainability, considering its four dimensions instead of a triple bottom line approach, the ability to be adapted to both large and small farms and lower design and implementation times [19]. SAFA has been compared with other methodologies for assessing sustainability by many authors [20,47,48]. This revealed strengths such as the wide range of topics covered, but also weaknesses including an excess of qualitative information. Gasso asserts in his study [20] that the 
environmental dimension can be assessed by a generic approach such as SAFA, while the economic and social dimensions would need more quantitative information. Again, De Olde et al. [48] underlined the need to contextualize generic approaches in order to provide reliable information. The SAFA framework is structured according to several hierarchical or aggregation levels (i.e., dimensions, themes and indicators). The more general level includes four dimensions of sustainability: good governance, environmental integrity, economic resilience, and social well-being. At an intermediate level it comprises 21 sustainability themes, which were defined by 58 sub-themes. At a more specific level, each sub-theme includes various indicators, for a total of 116 , which can be measured with a performance score on a scale from 1 to 5 . The SAFA indicators focus on performance rather than management systems, however alternatives indicators, i.e., target-based and practice-based indicators, are proposed by SAFA for contexts where performance-based indicators are not measurable [49]. As mentioned above, SAFA is applicable to large as well as small and medium-sized farms and to all stakeholders involved in the production process. Through the sustainability assessment, the methodology offers the opportunity to understand what improvement techniques can be implemented in order to increase the sustainable performance of farms. The SAFA framework provides an international reference tool for assessing the sustainability of agri-food enterprises, and its aim is to support the implementation of sustainable policy and effective management in the agrifood sector. The first step in a proper sustainability assessment is to identify the objectives and aims of the study. The next step is to describe the assessed entity, its size, sector, sphere of influence and impact generated [50]. Before starting it is necessary to choose the themes and sub-themes for which the study is to be carried out. The evaluator can decide to omit some of them in order to adapt it to the reality he/she is going to evaluate. In the next step, sustainability indicators and tools are selected, and standards for data collection are listed, determining the level of data quality through scoring [50]. The Accuracy Score is assigned according to the primary, secondary or estimated data using values 3,2 , and 1 respectively. Value 1 will be assigned to low quality data, 2 to moderate quality data and 3 to high quality data. The evaluation was carried out with the SAFA Tool Software (version 2.2.4.0) [51] which provides graphs of the results obtained in order to observe the data quality and performance of farms for each chosen indicator. These graphs therefore give an answer to the sustainability levels and highlight the dimensions that need improvement. The display of sustainability performance is represented by a radar chart in which a black line connects the various themes analyzed following a track light color code: very good/good practices (green), need for improvement (yellow/orange), or unacceptable (red) [50].

\subsection{Contextualization and Selection of Indicators}

The SAFA contextualization and indicator selection steps allow specific assessment framework modifications for small-scale producers, because these farmers face certain assessment challenges, including limited existing data and relevance of global indicators. The assessor can omit themes and indicators irrelevant to the context analyzed [16]. Taking into account the Sicilian context and the data availability, the themes listed in Table 1 have been excluded. The letters followed by a number (G1, G2, C3, S6) indicate the thematic areas. For each of them in Table 1 the reason for exclusion has been indicated, some themes are not applicable to the assessment of smallholders, others have not been considered because products are sold in their natural state while the theme "Cultural Diversity" has been excluded from the assessment as there are no other cultural entities within the territory. 
Table 1. List of sustainability themes and sub-themes excluded for being irrelevant within the assessment context.

\begin{tabular}{cc}
\hline Themes & Exclusion Grounds \\
\hline G1 Corporate Etichs & $\begin{array}{c}\text { Irrelevant for smallholder producers } \\
\text { Irrelevant for smallholder producers }\end{array}$ \\
G2 Accountability & $\begin{array}{c}\text { This theme has not been considered because products } \\
\text { are sold in their natural state, so there are no processing } \\
\text { (the farms sell the calves to other farms which then } \\
\text { fatten the animals) }\end{array}$ \\
S6 Cultural Diversity & There are no different cultural entities in the territory \\
\hline
\end{tabular}

\subsection{Case Studies and Data Collection}

The sample considered consists of ten farms operating in the mountain areas of Sicily. The choice of the sample was made on the basis of the representative structural characteristics of Sicilian livestock farms in order to carry out a stratified sampling; furthermore, the willingness of the farms to cooperate was considered in order to obtain reliable data. The answers obtained concern spontaneous declarations of the farmers interviewed, therefore in order to ensure the reliability of the data collected, 10 farms were analyzed.

For each, except for the size and number of animals, the same characteristics have been detected, which justifies the limited number of case studies considered. The farms are characterized by the presence of beef cattle livestock with organic method, these are family farming systems with their own production means. Regarding labor, generally all family members are involved in the activity and only two farms use seasonal workers when necessary. Livestock is raised on pasture for most of the year, with the exception of particularly harsh winters when the animal stables are mainly used during the night. In addition to animal husbandry, farms are dedicated to the production of cereals, especially wheat, and fodder, in accordance with the principles of organic farming and the usual crop rotations in order to maintain adequate soil fertility. Table 2 shows the main characteristics of the farms analyzed for the sustainability assessment.

Table 2. Characteristics of the analyzed farms $\left({ }^{*}\right)$.

\begin{tabular}{ccccccc}
\hline Farm & Crop & Livestock & Cattle No. & Employees No. & Family No. & Cultivated Land (ha) \\
\hline A & cereals/forage & beef cattle & 35 & 0 & 4 & 85 \\
B & cereals/forage & beef cattle & 35 & 0 & 4 & 150 \\
C & cereals/forage & beef cattle & 285 & temporary employed if necessary & 4 & 350 \\
D & cereals/forage & beef cattle & 50 & temporary employed if necessary & 3 & 80 \\
E & cereals/forage & beef cattle & 35 & 0 & 3 & 100 \\
F & cereals/forage & beef cattle & 41 & 0 & 4 & 60 \\
G & cereals/forage & beef cattle & 50 & 0 & 3 & 146 \\
H & cereals/forage & beef cattle & 30 & 0 & 2 & 60 \\
I & cereals/forage & beef cattle & 25 & 0 & 2 & 50 \\
J & cereals/forage & beef cattle & 35 & 0 & 4 & 77 \\
\hline
\end{tabular}

${ }^{*}$ Our elaboration. Animals are expressed in LU (Livestock Unit).

The data used to carry out the sustainability assessment were collected between November 2020 and January 2021 through direct interviews with ten farmers. Primary data was collected using a questionnaire containing semi-structured questions. The choice fell on the latter in order to leave farmers the possibility to elaborate autonomously the answer, they are used in the research activities as they refer to defined criteria in that a pre-established model of correct answer is used for evaluation and interpretation. Each survey took between 60-120 min to answer the questions based on the SAFA indicators. The questionnaire was translated from English into Italian, while the answers were entered into the software in original language. In addition to the interviews, direct visits and observations were made to all farms, thanks to the farmers' availability. The sample size 
has been chosen according to the research objectives. The survey was conducted with the full consent of the participants, which included the terms and the conditions that were expected from both researchers and participants. These included voluntary participation, withdrawal of the participant at any given time, data protection (guaranteeing anonymity and privacy as required by EU Reg. 2016/679 and Legislative Decree 101 of 10 August 2018) and the dissemination of data in aggregate and not in individual form.

\section{Results}

The following radar charts in Figure 2 provide an overview of the sustainability levels in each of the four SAFA dimensions of the organic farms considered. The performance polygons fall into a range from green (illustrating "good performance"), to yellow/orange (illustrating "need for improvements"), or red (named "unacceptable performance"). The white color represents the excluded themes.

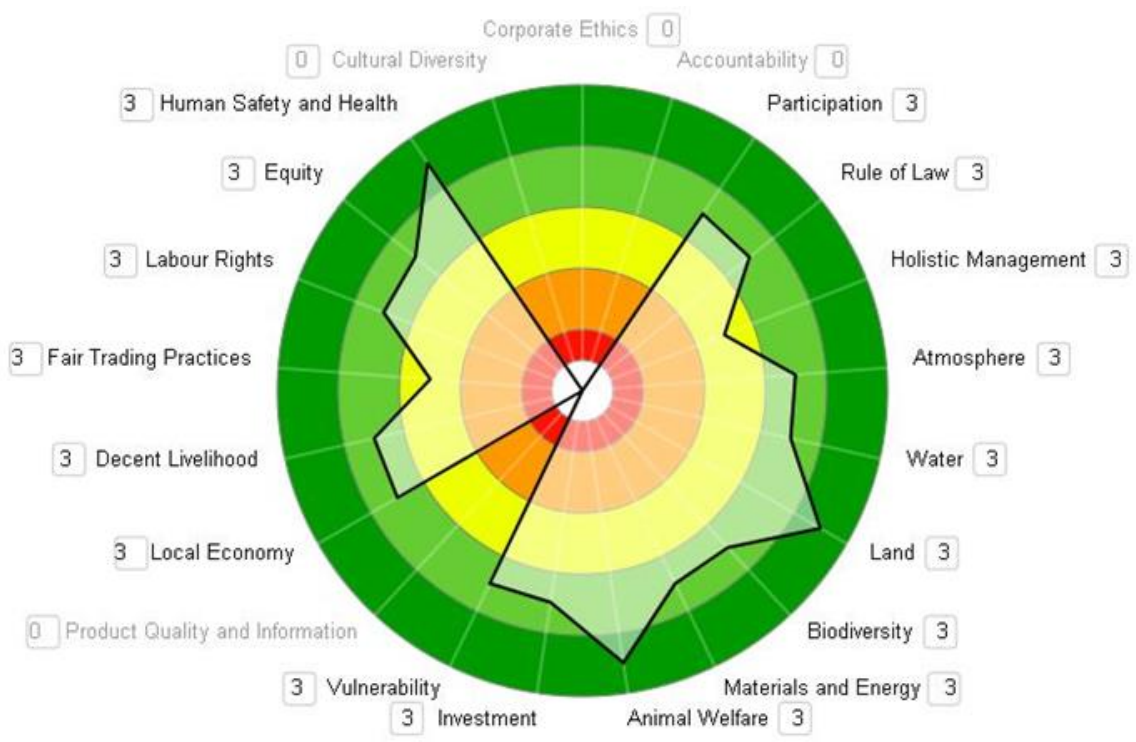

Farm (A)

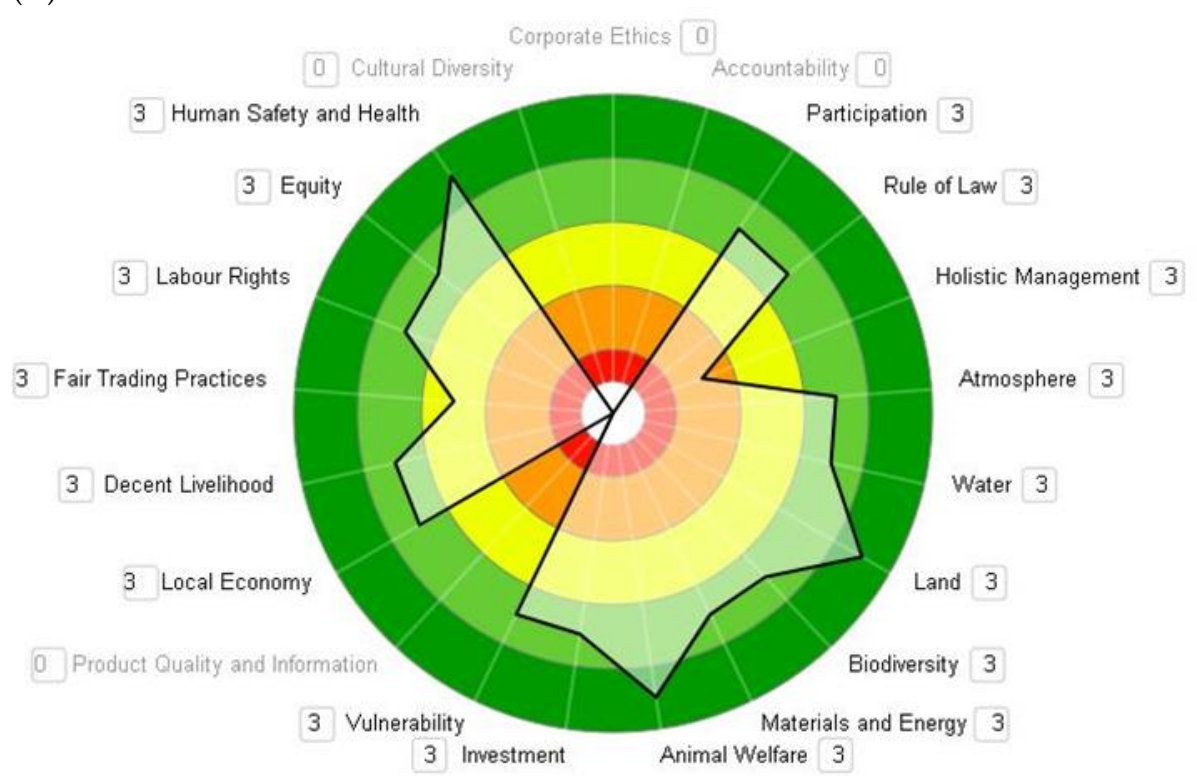

Farm (B)

Figure 2. Cont. 


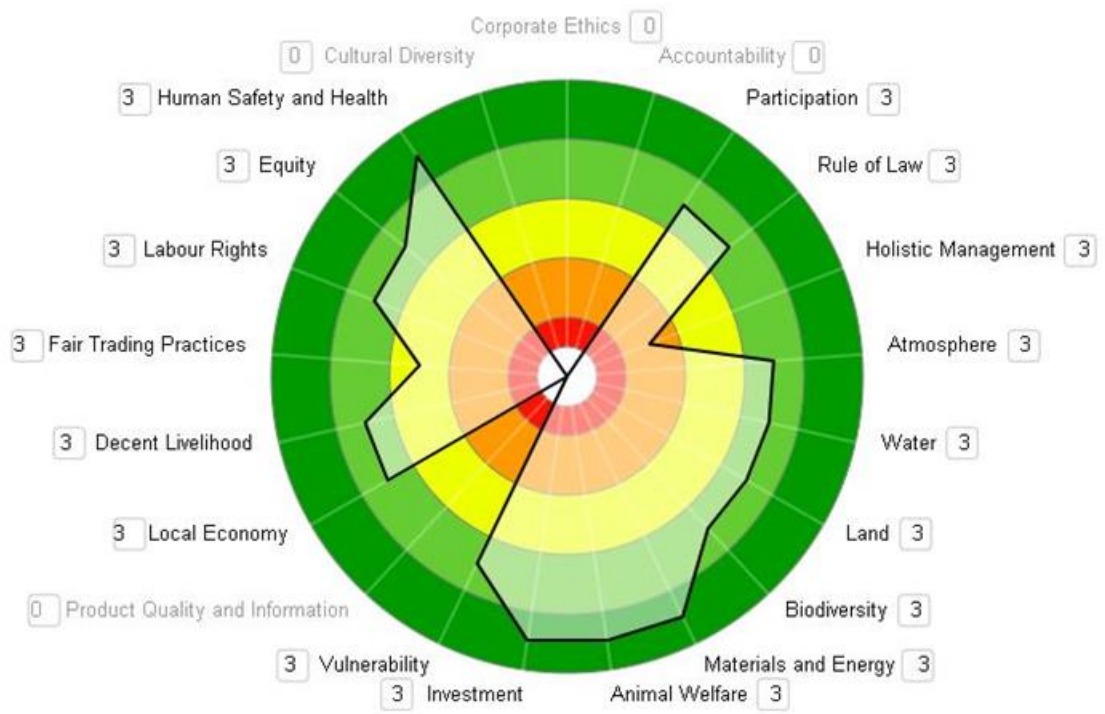

Farm (C)

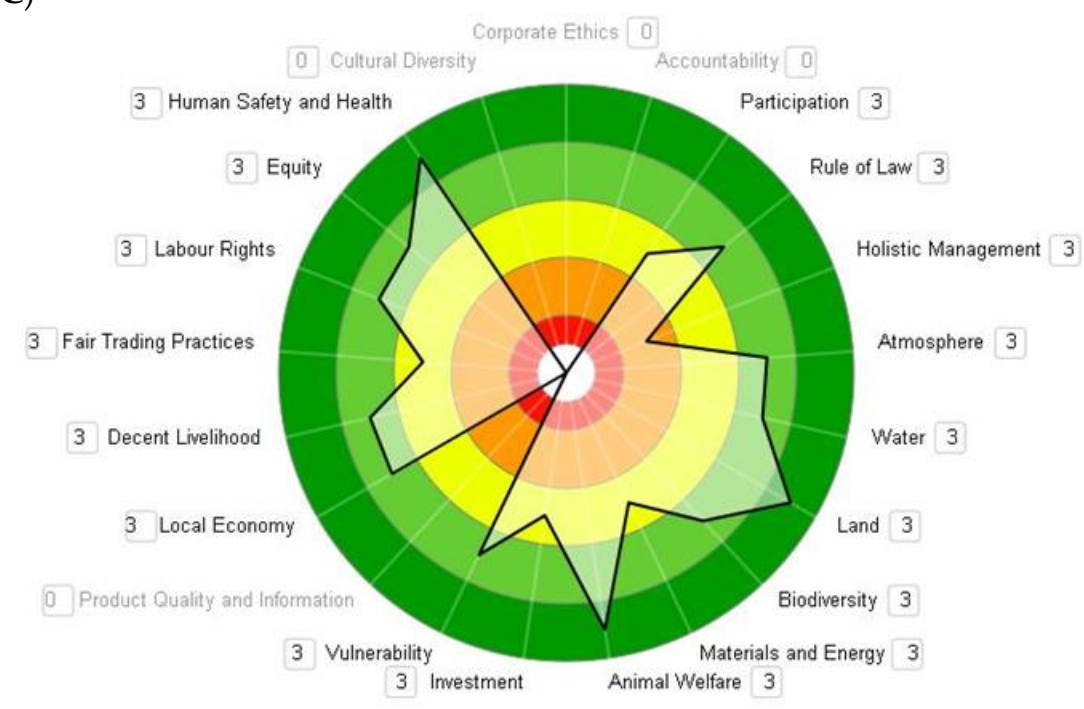

Farm (D)

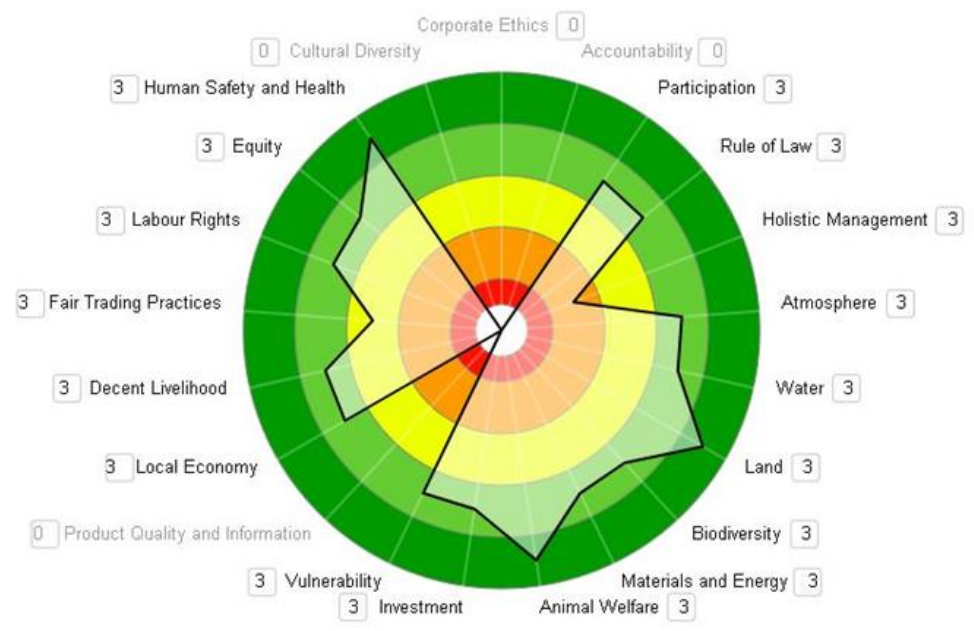

Farm (E)

Figure 2. Cont. 


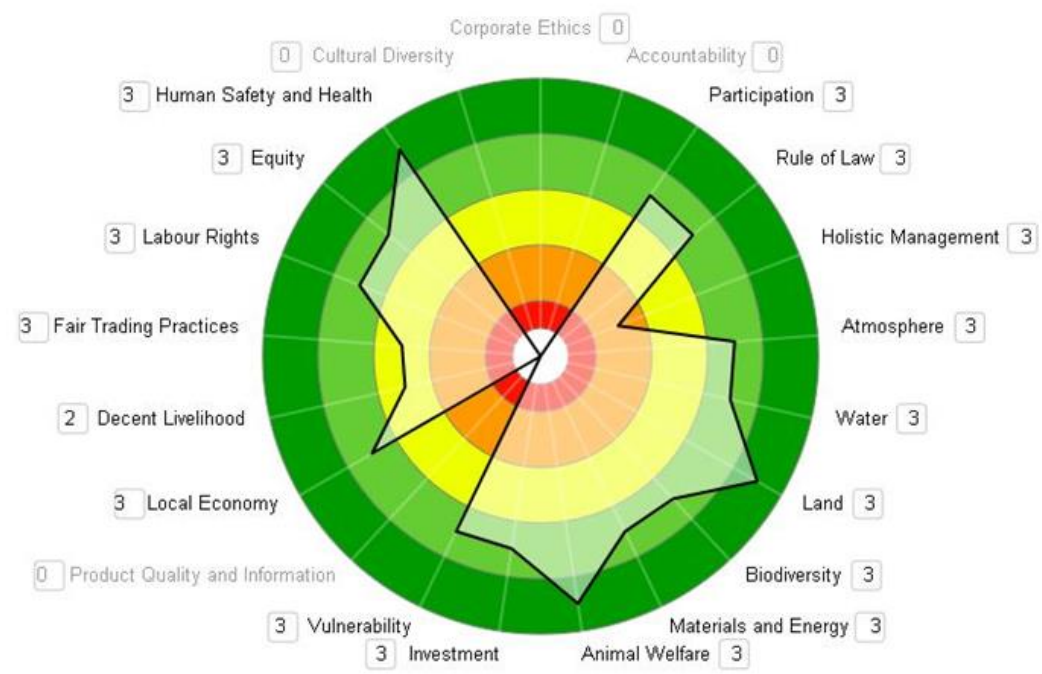

Farm (F)

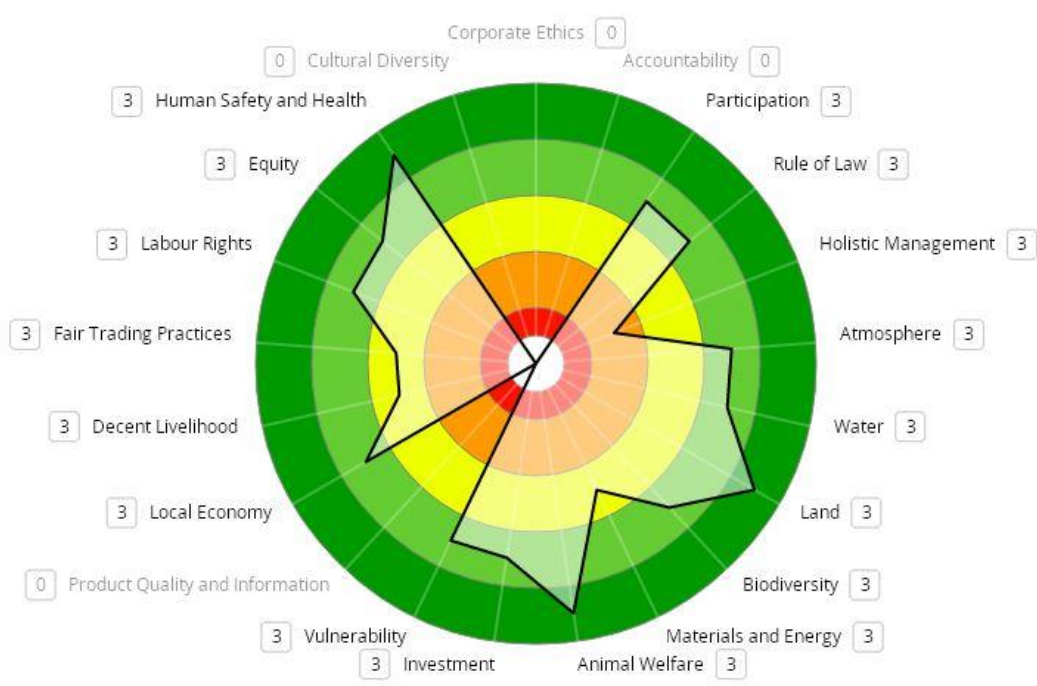

Farm (G)

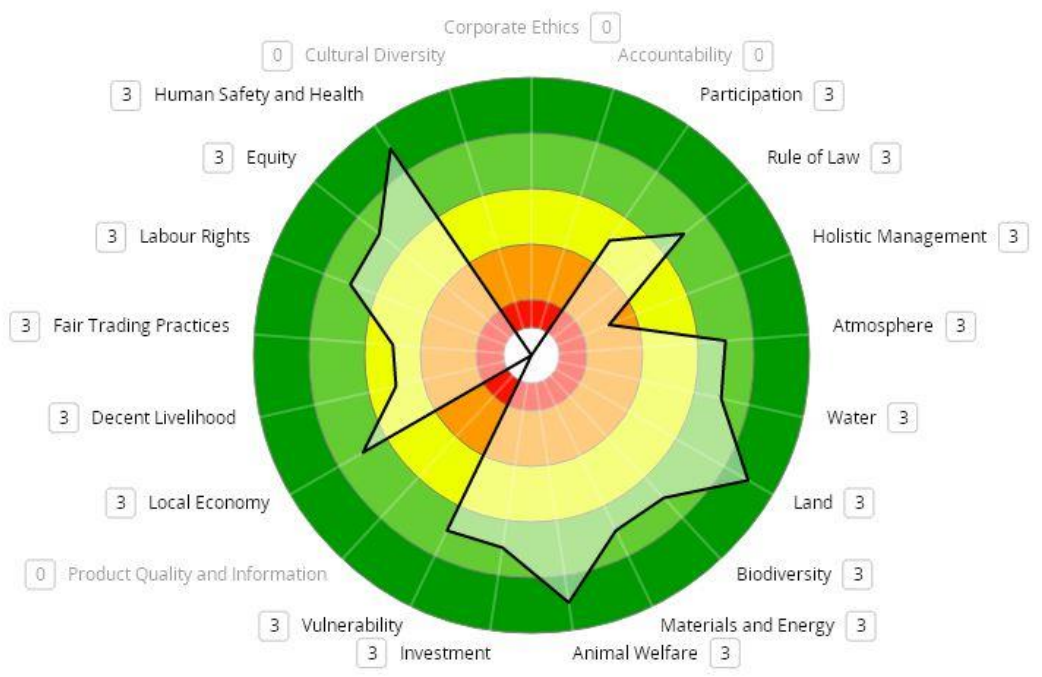

Farm (H)

Figure 2. Cont. 


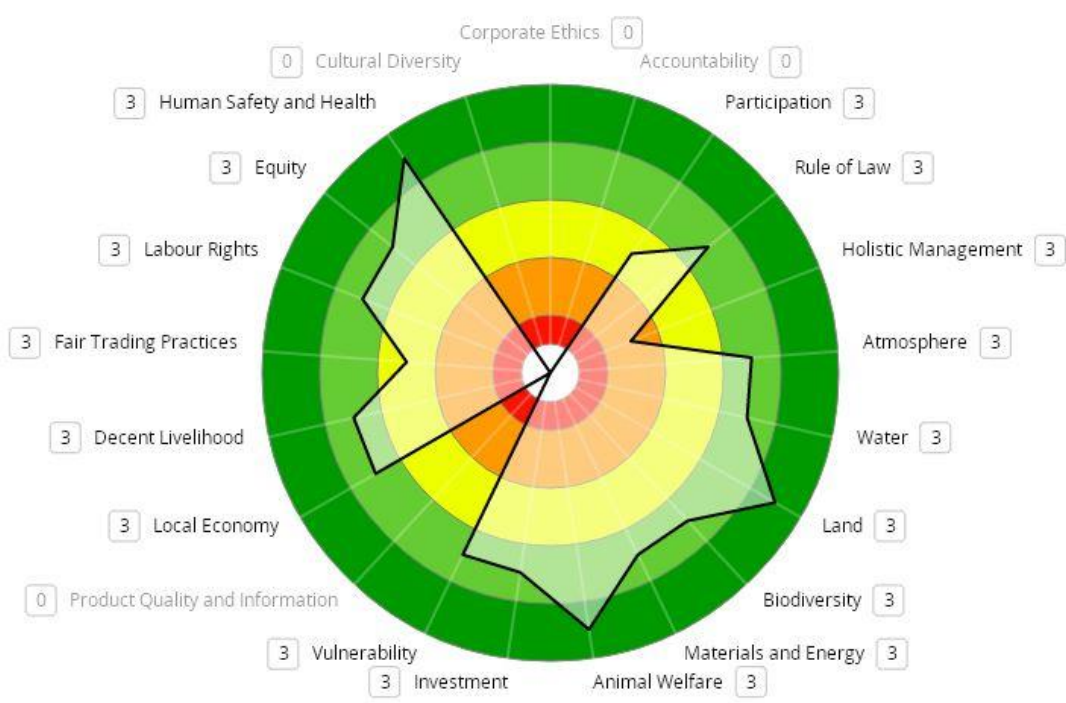

Farm (I)

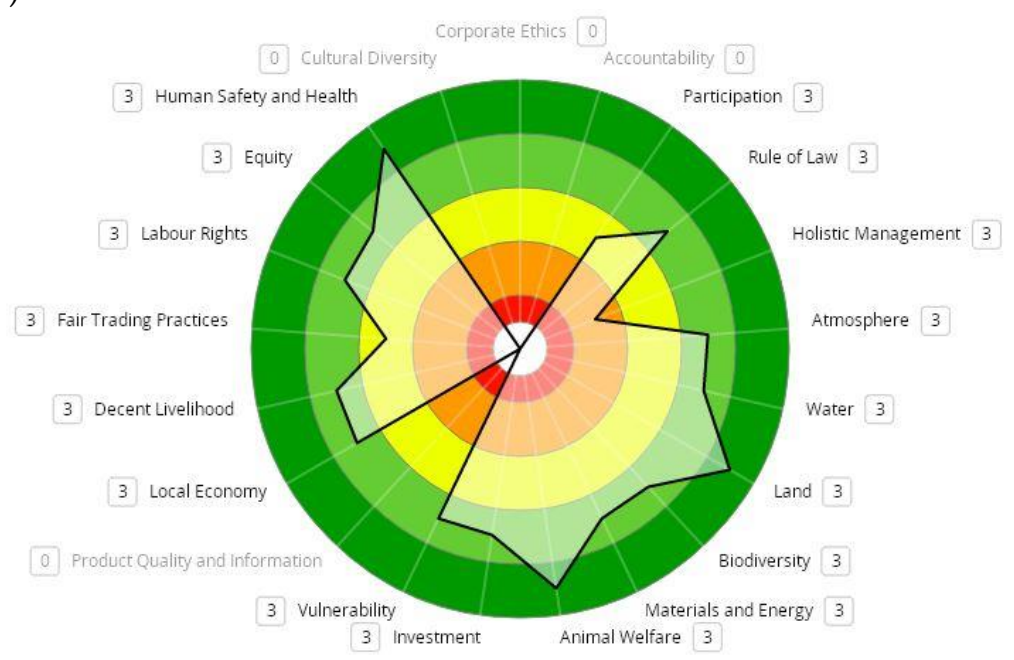

Farm (J)

Figure 2. Farm (A-J) Results of the sustainability assessment of organic livestock farming with SAFA, by individual indicator and production unit.

The numbers outside the graphs and next to the themes mean the data quality and accuracy score, where 0 represents excluded themes, 1 represents low data quality (data based on estimation), 2 represents moderate quality data (data based on secondary data), 3 represents high quality data (data based on primary current data, not later than two years old) [49].

The study is based on recent, high-quality data (number 3). Of the organic farms analyzed, farm A, B, D, E, F, G, H, I and J scored dark green in the thematic areas: Land, Animal Welfare, Human Safety and Health; farm F differs from the others in having obtained a dark green score in the same areas except for the Land category and in Materials and Energy and Investment. The results obtained in the other thematic areas showed positive scores characterized by the color light green, with the exception of Participation where farms D, H, I, and J scored yellow and Holistic management where farm A scored yellow while the others orange. In the Fair Trading Practices category all farms scored yellow. Farm D and G also scored yellow in the thematic areas of Materials and Energy and Investment, while farm F and $\mathrm{H}$ scored yellow in the Decent Livelihood category. None of the farms analyzed scored red in the categories considered. The results achieved by organic 
farms are positive thanks to the agro-ecological approach they follow. This allows farms to achieve good levels of sustainability despite the improvements that can still be made.

\subsection{Good Governance}

\subsubsection{Participations}

Participation refers to the involvement process of all stakeholders, which include all those affected by the activities of the enterprise. In this case, the sub-themes are characterized by stakeholder dialogue, grievance procedures and conflict resolution, therefore all stakeholders are entitled to complaint procedures without the risk of negative consequences, and possible conflicts are resolved through dialogue based on respect, mutual understanding and equal power. Farms A, B, C, E, F and G scored green because they always engaged in dialogues with stakeholders for example to decide on the best time to sell cereals or to procure feed if it is necessary. Another topic of discussion between farmers and stakeholders was the right of passage on some land in their possession, they were able to respect the rights of neighboring farms by resolving disputes. Farms D, H, I and J scored yellow because it failed to maintain a stable relationship with the seed and feed suppliers, and had disputes with the reference slaughter-house by having to find another one to take the cattle.

\subsubsection{Rule of Law}

The thematic area "Rule of Law" is understood by the United Nations as a governance principle, according to which all persons and entities are accountable to publicly promulgated laws, i.e., compliance with legislation [51]. The sub-themes covered in this case are: the legitimacy; remedy, restoration and prevention; civic responsibility; free, prior and informed consent and tenure right. The organic farms in question scored green in all the indicators considered, demonstrating that they comply with the legislation regulating activities and, above all, that they have identified the necessary instruments to remedy any violations and restore their effects. The farms have also shown that they do not restrict the shareholders' rights in any way and have demonstrated their property rights and free access to the resources used for their production process.

\subsubsection{Holistic Management}

Holistic management is understood as the continuous commitment of a farm to improve all dimensions of sustainability in order to foster the sustainable development of the society in which it operates. This is represented by two sub-themes: sustainability management plan and full-cost accounting. Planning sustainability in written form is an innovation for enterprises that often do not have a structured plan despite being in line with agroecological principles and sustainable development. Being smallholders, they do not have a formal plan but set the objectives they intend to achieve informally, so they obtained an orange score indicating their commitment to all four pillars of sustainability despite not having a written plan. The score obtained is justified by the lack of a detailed accounting plan, this is not limited to recording only the cost elements incurred by the farm but also implies environmental accounting in which each farm must highlight all opportunities offered by the reference ecosystem. These issues are still not completely clear to the farmers interviewed and therefore the score is consistent with the findings.

\subsection{Environmental Integrity}

\subsubsection{Atmosphere}

Agricultural and mainly livestock activities influence air characteristics and quality. This is considered in SAFA within the thematic area "Atmosphere". The organic farms analyzed are committed to the reduction of GHG emissions, despite this, they are not characterized by an articulated written plan with all the measures implemented, with the exception of farm $\mathrm{C}$, which is starting to keep a written record of the operations aimed at reducing GHG emissions. The activities implemented by companies in order to reduce 
GHG emissions concern: the fertilization management plan using organic material and the correct timing of application, crop rotation, minimum tillage and incorporation of crop residues. The machines used have an adequate power to the needs of the operations therefore there is no risk of oversizing the machinery compared to the real needs that lead to the increase of the emissions. Regarding the management of pastures, the intensity and timing of grazing are respected and leguminous fodder crops with higher productivity are cultivated. Similarly, the ten companies do not have a written plan to reduce air pollutants, but they are committed to this by implementing good fertilization practices and maintaining a permanent soil cover to reduce wind erosion that leads to the release of dust into the air. Farms A, B, C, D, E, G, H, I, and J received a green score as they implement the above-mentioned practices every agricultural year, while farm $\mathrm{F}$ received a yellow score as it stated that it often did not implement all the necessary measures to reduce air pollutants due to time constraints.

\subsubsection{Water}

Water plays a key role in sustainability topics. In the SAFA study, farms' water-saving practices are monitored in order to assess their efficiency. The ten farms analyzed do not have a written plan in which to set a target to reduce water use or potential pollutants, but they are committed to practices such as proper management of water used to clean stables by optimizing the pressure and diameter of the hoses and cultivating crops that do not require irrigation but only make use of annual rainfall events. The situation is similar in the case of water cleanliness, no written plans were found in all farms, but as they are located at distances of more than $1 \mathrm{~km}$ there is no risk of contamination due to their activities; all farms also commit to activities such as organic soil management, the use of drainage furrows, the non-use of pesticides, which would increase pollutants in both surface and ground water, and the use of mobile watering facilities for livestock. While many improvements can still be made, the score of all farms in this area is green due to the reduced possibility of water contamination.

\subsubsection{Land}

The Safa tool pays particular attention to the soil resource, the farms A, B, D, E, F, G, H, $\mathrm{I}$, and $\mathrm{J}$ in this area scoring dark green, which denotes excellent results as they implement practices such as organic soil management and the provision of organic fertilizers including manure to increase the organic matter content, minimum tillage to reduce erosion and compaction, the cultivation of nitrogen-fixing crops to increase the nitrogen content of the soil, and green manure to limit wind erosion. Visits to the farms have shown that more than $80 \%$ of the land used is in excellent condition and free of erosion. Farm C, unlike the others, received a light green score; it is committed to implementing the same practices, but a higher percentage of land affected by degradation was found, also as a consequence of a larger surface, which makes management more difficult.

\subsubsection{Biodiversity}

Regarding biodiversity, the ten farms analyzed lack an organized and written plan for the conservation of the habitat in order to improve its functional processes. In this context the Ecosystem services include: soil functioning, nutrient cycling, pest and climate regulation, diversity of plants and animals, that contribute to establishing the balance within the same. The practices implemented for habitat conservation are: environmentally friendly agroecological approaches to both tillage and fertilization plans, mechanical weed control, no use of synthetic pesticides, crop rotations using nitrogenous species and soil cover. The functionality of agroecosystems is also influenced by the spatial structure of the landscape; on the farms analyzed, the structural diversity found in the soils affected by agricultural activities is equal to the sur-rounding landscape, i.e., no cases of monoculture or practices affecting the development of the habitat was detected. The combination of these 
practices, but above all the extensive crop rotations and the abandonment of monocultures, led the ten farms to score green in this thematic area.

\subsubsection{Material and Energy}

It is important to consider the amount of materials reused in the production process or correctly disposed of when assessing the sustainability of farm. The two key aspects of this thematic area are the share of recycled and renewable materials and the reduction of material intensity of production. The farms considered in the study have tried to reduce the amount of non-recyclable materials in recent years, their cultivation process and livestock farming do not require the use of large quantities of non-renewable or non-recyclable materials, just think that by not using synthetic pesticides or herbicides the farms do not use plastic containers. Bags used for crop seed are reused on farms for other purposes, as are ties reused in animal pens or for other functions. Little attention was paid to renewable energy sources by entrepreneurs, with the exception of company $\mathrm{C}$ which has a photovoltaic panel system that supplies $50 \%$ of the energy used in the farm. For these reasons, companies A, B, E and F received a light green score, companies D, G, H, I, and $\mathrm{J}$ received a yellow score as, despite their commitment to the practice of reducing nonrecyclable materials, it often used them and had difficulty in disposing of them properly, while company $F$ received a dark green score as it is the one that pays the most attention to the subject and has renewable energy sources.

\subsubsection{Animal Welfare}

Another important focus area is animal welfare. The farms surveyed stated that they are free of sick or injured animals, are committed to minimizing the use of veterinary medicines and ensuring all animal needs are met, therefore $100 \%$ of the animals were in good health at the time of the survey. All animals are supported in their normal needs and sources of stress are reduced, the farms sell the calves to other farms which then fatten the animals. The farms also favor grazing and only use stables during the coldest days and nights, or when birth dates are coming up. As a result of the practices mentioned the farms scored dark green.

\subsection{Economic Resilience \\ 3.3.1. Investments}

In the SAFA tool, investments are viewed from a microeconomic perspective and are understood as the share of money spent on improvements that can make the farm more sustainable [51]. Farms have made investments to improve the production process, such as renewing the machinery fleet in order to reduce processing emissions, more energy and water-efficient barn cleaning systems and, where they have to employ seasonal workers, they rely on local resources to meet the needs of the community. By allocating money for the purchase of new land or equipment, companies improve their capacities and profits in the long term. This is necessary in order to keep farms competitive. The net profit of enterprises is always positive, but this does not mean that every year there is an increase, it often remains unchanged. Based on the above, all farms except $C$ and $D$, obtained a light green score as they demonstrated their positive attitudes towards investments. Farm D received a yellow score as it is the only one that did not show a solid commitment to this issue by making only the necessary investments. In contrast, Farm $C$ was the only one to receive a dark green score as it has made major changes to its structure such as the use of renewable energy.

\subsubsection{Vulnerability}

The thematic area of vulnerability helps to understand the ability of farms to supply the same quantity and quality of products over the years in order to guarantee a high standard of quality and to expand the range of offers by diversifying their products. In this sense, the companies analyzed are able to guarantee the quality of their products, but not 
always the quantity, which can easily be influenced by external factors such as the climate, especially in a mountainous environment, and it is also difficult for them to diversify their products, as they mostly have a low dynamic product portfolio. With regard to supply channels, farms are able to maintain stable relationships with suppliers and if they fail to provide what they need, entrepreneurs have replacement channels for emergency situations. The economic vulnerability of a farm is also assessed through financial external sources, whether formal (e.g., banks) or informal (e.g., loans from family or friends). All these aspects, even if they can be improved, guarantee an economic return to the farms analyzed that allows them to cope with the risk situations, therefore the score obtained is green in all cases.

\subsubsection{Local Economy}

The local economy should be understood as the contribution made by farms to the development of economic conditions in the area in which they operate. As mentioned above, the organic farms analyzed are characterized by a family-run system and only seasonally use external workers who in any case belong to the place where they operate. In all cases, regular payment of both municipal, regional and national taxes was found, thus contributing significantly to the public budget. Finally, the supply of materials needed for the activities comes from the same territory as the farm. Although they can be improved, e.g., by hiring a stable workforce, the companies contribute to the development of local economy and have therefore been awarded the green score.

\subsection{Social Well-Being}

\subsubsection{Decent Livelihood}

The thematic area examined refers to the living conditions of entrepreneurs, the surveys showed that farms A, B, C, D, E, I and J are able to make time for their families, manage to carve out time for themselves, be able to organize holidays during which they are replaced by seasonal workers and have time to prepare meals appropriate to a healthy lifestyle. They also stated that they live a life free of oppression, in peace and with adequate time for family needs. The subsistence wages paid by employers to family members who work with him are adequate to ensure a decent livelihood that enables them to meet the costs of food, education, clothing, health care, leisure and savings. For this reason they received a green score, while companies $\mathrm{F}, \mathrm{G}$ and $\mathrm{H}$ received a yellow score because they stated that it does not always manage to organize their work in such a way as to spend free time with the family or to be able to organize holidays.

\subsubsection{Fair Trading Practices}

The theme "Fair Trade Practices" includes legal rights, which allow farmers to have access to markets where fair prices are negotiated. Farms scored yellow because for livestock sales they negotiate the price and therefore have a good bargaining position in the marketing system, while for cereal sales they are subject to the price and have no decision -making power.

\subsubsection{Labor Rights}

The farms analyzed are characterized by a family-based management system and therefore, as repeatedly stated, only employ seasonal workers in situations of necessity. the latter are paid according to the law and have a regular contract of employment, also they are in no way obliged to carry out their duties and are free to leave if they need to. The entrepreneurs specified that they had never employed workers under the age of 18 and therefore no cases of child exploitation were detected. 


\subsubsection{Equity}

The ten entrepreneurs interviewed scored green in this thematic area because they respect all workers' rights and do not discriminate in any way (based on creed, gender, age, political orientation, nationality, color, etc.).

\subsubsection{Human Safety and Health}

The score for the ten companies in this area is dark green because all workers, both family members and seasonal workers, are always made aware of the dangers at work, are trained in the operation of the machines and work is carried out under appropriate health and safety conditions. The workplaces are clean, built in accordance with building regulations and the equipment provided is safe, further-more, all workers are guaranteed immediate access to medical care in the event of an accident at work and adequate insurance cover. The activities carried out by the companies also do not harm the community's lifestyle and are in no way damaging to its health.

\subsection{Comparison of the Sustainability Level for Each Dimension Considered}

The SAFA survey results reveal a unique livestock farm model in the Sicilian mountain areas. The organic farms reported very similar values, reflecting a homogeneous entrepreneurial reality in the territory.

The following is a comparison between the farms considered in the study for each dimension of sustainability (Good Governance, Environmental Integrity, Economic Resilience and Social Well-Being). A numerical score was assigned to each color in the radar graphs: red corresponds to value 1, orange to 2, yellow to 3, light green to 4 and dark green to 5 . In this way, the average values obtained by the individual farms in each thematic area were taken into account for all dimensions of sustainability.

\subsubsection{Good Governance}

In the Good Governance dimension the results of organic farms are not very different from each other. The best score was obtained by farm 1, which, compared to the others, showed that it has long-lasting relations with stakeholders and always manages to overcome any disputes. All farms have demonstrated a good ability to deal with the risks that can occur in the production process, but they can still make improvements, as demonstrated by all ten farms' score of around 3. Possible practices to implement in order to improve the dimension of Good Governance are to increase the stakeholders' involvement, to initiate frequent dialogues with them to solve any problems in a timely manner and to have more lasting relationships with suppliers.

\subsubsection{Environmental Integrity}

In the environmental integrity dimension, the results are positive for all farms considered. Since these are organic farms without pesticides, herbicides and they using organic fertilizers, respect for the environment comes first. Entrepreneurs have shown great commitment to the purchase of environmentally friendly machinery and the application of sustainable practices such as minimum tillage and green manure. The best results were obtained in the Land theme area thanks also to the abandonment of monoculture and the use of crop rotation, and in Animal Welfare thanks to excellent livestock management. All farms received an average score of 4.3, however they can still improve their performance in terms of increasing the share of energy from renewable sources and reducing non-recyclable materials.

\subsubsection{Economic Resilience}

The economic resilience dimension obtained a positive result for all the farms analyzed, the average score obtained was 4. Only farm D scored lower than the others (score 3.7) because its activity often did not produce adequate remuneration for the entrepreneur's 
and his family's needs. Also in this dimension, farms can engage in order to implement changes such as hiring local workers that would increase the local economy.

\subsubsection{Social Well-Being}

In social well-being dimension good sustainability results, score 4 , are obtained by all farms with enterprise F, G and H performing lower than the others (score 3.8). Entrepreneurs reported that they are able to carve out free time to dedicate to family and activities. Furthermore, as family-run businesses, they only make use of external workers on a season-al basis, for whom all contractual and safety at work regulations are respected and timely medical treatment is guaranteed in the event of infection.

In order to analyze the differences that have emerged in the study of the literature on this topic, the research carried out by Gayatri et al. [49] in Indonesia and related to Smallholder Beef Cattle Farming was considered. This takes into account three different types of business systems of which we only consider the family farming system to better emphasize the differences with our study. Indonesian farms performed significantly lower than those analyzed in our study in all areas, with the exception of similarities in the sub-themes of Participation and Equity. They are severely restricted as a result of a lack of investment, which has an impact on the proper management of land, animals and water used for activities. "The results of the analyzed farms show that the SAFA Sustainability Performance was worst for the family farming ... However, this study suggests that it can be more an issue of access to resources. The access to economical resources appears to be lower for the smaller farms (family farms), however, once a certain level of economic resources is reached, the sustainability performance may not have significant increases [49]". The same authors state that therefore the greatest scope for improvement in terms of sustainable performance is in family systems. It is a greater knowledge of sustainability in the broad sense thanks to a wider process of information dissemination, greater awareness of good practices in terms of impact and easier access to sources of investment that allows Sicilian livestock farms to perform better than Indonesian ones.

In recent years, scientists have focused their efforts on creating beef, in the form of burgers or patties, in the laboratory. Typically, the production of a cultured burger begins with the collection of muscle cells from a live cow, and proceeds with their culture in the Lab [52]. The Sicilian livestock model, even if with its limits, is a sustainable alternative to both intensive breeding and lab meat whose possible repercussions on human health are not known

\section{Discussion}

The dimension of Good Governance refers to long-term business planning. All production activities will have both positive and negative effects in the future and for the farmer to plan for the distant future would be practically impossible [53]. The findings show the absence of written plans. This may be a shortcoming in producing sustainably for a longer period, which may affect both economic and environmental performance. The "good governance" dimension can be understood as a horizontal dimension with direct repercussions in other dimensions [54]. Farms that optimize the governance dimension can improve overall sustainability performance [55]. There is a need for farmers to increase their knowledge in this context in order to improve their production and economic performance, thereby helping stakeholders and local communities to grow.

In the Environmental Integrity dimension results show that environmental sustainability is linked to the maintenance of plant and animal biodiversity. The increase in cultivated land and urban areas has led to profound changes in land use and agricultural intensification that are the most dominant drivers of global biodiversity loss, altering its composition, distribution, abundance and functioning of biological diversity [39,40]. Through high levels of biodiversity using locally adapted seeds, indigenous breeds, and incorporating soil and water protection practices, there are positive effects on the profitability of the farm, reducing its vulnerability to external risks, and strengthening food security and 
sovereignty [50]. In order to restore ecosystem balances, it is therefore necessary to reestablish an extensive and more sustainable livestock farming system that covers environmental, social and ethical needs.

With regard to the dimension of "Economic Resilience", it is important to emphasize that all farmers diversify their source of income based on cereal and forage production as well as on livestock farming. Diversification is also a best practice that reduces off-farm inputs while increasing product range [21]. Increasing economic investment would also increase the resources needed to reduce environmental impact, use renewable energy sources and modernize animal shelters to make them more sustainable. Furthermore, it should not be overlooked that an increase in the economic well-being of a farm would allow it to employ more workers by offering them advantageous contracts. This shows, on the one hand, how the areas of sustainability considered in Safa are connected to each other and, on the other hand, the possibility of growth that Sicilian organic farms have despite their achievements and positive results. The above relates the environmental dimension to the economic one.

The positive results in the social well-being dimension highlight how active farmers feel in the growth of their community. It is there that the purchase of goods and services and the seasonal labor they need take place. The development of local networks becomes necessary for the achievement of sustainable development [21].

The pursuit of sustainability, besides being a goal, is a path to be built and continuously improved. The reality of Sicilian livestock farming can still be improved in order to make it fully sustainable.

SAFA can be used as a training tool used by both farmers (e.g., by voluntary uptake) and the government agricultural institutions, such as the Livestock and Fishery Offices, which aim at assisting small-holder farmers with little resources to improve their production and performance in terms of sustainability [49]. It allows farmers to become aware of their farms' weaknesses and at the same time find a solution to overcome them. It may help to create synergies between the practices required to meet their needs and the concerns of a wide range of stakeholders, from farmers to policy-makers [49].

The work presented aims to emphasize that when dealing with the four areas of sustainability, a holistic approach is necessary, it is not possible to focus only on one of them. An agricultural system cannot be considered sustainable if it does not produce adequate food supplies and economic rewards to farmers despite being environmentally friendly. Thus agricultural systems with high levels of production cannot be considered sustainable if they neglect the environmental sphere by using a large amount of inputs [56].

The sustainability assessment of farms in mountain areas of Sicily, using the SAFA methodology, has not been carried out before. The results of the assessment can encourage farmers to make improvements within each individual farm, but also offer an important tool to provide recommendations on sustainability issues that should be implemented in the future [50]. The methodology used is an innovative tool that highlights the peculiarities of Sicilian livestock farming. It is an agro-ecological model that offers a sustainable alternative to the advancing threat of lab meat.

The efforts of European Community and local institutions focused on agroecological transition are part of a scenario divided in two and that sees on the one hand the intensive farming methods and on the other the Sicilian paradigm, also found in other Mediterranean geographical contexts of European Union. The institutional objectives are to transform intensive livestock farming, characterized by a significant environmental, social and economic impact, into sustainable livestock farming in order to reduce both emissions and consequently the cost of the latter to societies.

\section{Conclusions}

The research is based on the study of organic livestock farms, located in the mountain areas of Central Sicily. The survey carried out in order to measure the sustainability level in the four dimensions considered by the SAFA tool has made it possible to outline the 
typical characteristics of the farms analyzed, which highlights a homogeneous model characterized by good levels of sustainability despite the numerous improvements that can be implemented. The principles of organic farming and the adoption of practices that respect the agroecological approach have resulted in medium-high levels of sustainability on all the farms considered. It is precisely the agroecological approach that makes farms environmentally friendly and guides them towards a holistic view of sustainability. Farmers can undoubtedly improve their yields in sustainable terms in order to improve the situation on our planet by not excluding the possibility of increasing the local economy in which they operate, for this reason the study highlights the need to facilitate access to knowledge and economic funds. Safa, in addition to offering the measurement of the sustainability level of farms, offers a food for thought for local political bodies that can use it as a tool for studying the territorial situation. It can also be used by other farmers to understand how to achieve sustainability or to measure the performance of their farm.

This is, among other things, compatible with the strategy of the "New Deal EU" and the corresponding "Biodiversity 2030" and "Farm to Fork EU". It is at the heart of the Green Deal. It addresses comprehensively the challenges of sustainable food systems and recognizes the inextricable links between healthy people, healthy societies and a healthy planet [57].

Today more than ever it is necessary to provide farmers with easily usable operational tools and a participatory dialogue with government bodies [58] in order to pursue a single objective, the achievement of sustainable development.

Future research developments will see the integration of other methodologies for measuring the impacts of the production cycle, with Life Cycle Assessment (LCA) assessment, and the extension of the scope to other territories in order to integrate knowledge.

Author Contributions: The work is the result of the full collaboration of the all authors, who dealt with the formal analysis. All authors have read and agreed to the published version of the manuscript.

Funding: Research project "Starting Grant", Principal investigator Alessandro Scuderi, funded by PIAno di inCEntivi per la Ricerca di Ateneo (PIACERI) UNICT 2020/22 line 3, University of Catania.

Institutional Review Board Statement: Research was limited only to direct observation of animals and collection of information suggested by farmers, without any direct and indirect treatment of animals.

Informed Consent Statement: Informed consent was obtained from all subjects involved in the study.

Data Availability Statement: The data is not made public as it is digitally stored within the SAFA software.

Conflicts of Interest: The authors declare no conflict of interest.

\section{References}

1. Sustainable Development Goals. Available online: https://sustainabledevelopment.un.org/content/documents/4538pressowg1 3.pdf (accessed on 7 January 2021).

2. Lewandowski, I.; Härdtlein, M.; Kaltschmitt, M. Sustainable crop production: Definition and methodological approach for assessing and implementing sustainability. Crop. Sci. 1999, 39, 184-193. [CrossRef]

3. Brokensha, D.W.; Warren, D.M.; Werner, O. Indigenous Knowledge Systems and Development; University Press of America: Lanham, MD, USA, 1980; p. 473.

4. Martinez Castillo, R. Agroecologías: Atributos de sustentabilidad. InterSedes 2002, 3, 25-45.

5. Altieri, M.A.; Toledo, V.M. The Agroecological revolution in Latin America: Rescuing nature, ensuring food sovereignty and empowering peasants. J. Peasant Stud. 2011, 38, 587-612. [CrossRef]

6. Guzmán, E. De la Sociología Rural a la Agroecología; Icaria Editorial: Barcelona, Spain, 2006; p. 251.

7. Food and Agriculture Organization of the United Nations (FAO). The 10 Elements of Agroecology: Guiding the Transitions to Sustainable Food and Agricultural Systems. Available online: http:/ /www.fao.org/3/I9037EN/i9037en.pdf (accessed on 7 January 2021).

8. Battaglini, L.; Bovolenta, S.; Gusmeroli, F.; Salvador, S.; Sturaro, E. Environmental sustainability of Alpine livestock farms. Ital. J. Anim. Sci. 2016, 13, 431-443. [CrossRef]

9. MEA. Ecosystems and Human Well-Being; Millennium Ecosystem Assessment; Island Press: Washington, DC, USA, 2005. 
10. EEA. Europe's Ecological Backbone: Recognising the True Value of Our Mountains; Agricultural Ecosystems; European Environment Agency Publ.: Copenhagen, Denmark, 2010.

11. EEA. 10 Messages for 2010; Agricultural ecosystems; European Environment Agency Publ.: Copenhagen, Denmark, 2010.

12. Hacking, T.; Guthrie, P. A framework for clarifying the meaning of triple bottom-line, integrated, and sustainability assessment. Environ. Impact Assess. Rev. 2008, 28, 73-89. [CrossRef]

13. Spangenberg, J.H. Sustainability beyond Environmentalist: The Missing Dimensions; Governance for Sustainable Development Working Paper No. 2; Verl. Westfälisches Dampfboot: Münster, Germany, 2004.

14. Devuyst, D. Introduction to sustainability assessment at the local level. In How Green Is the City? Sustainability Assessment and the Management of Urban Environments; Devuyst, D., Ed.; Columbia University Press: New York, NY, USA, 2001.

15. Sarandón, S.J. The development and use of sustainability indicators: A need for organic agriculture evaluation. In Proceedings of the XII International Scientific Conference (IFOAM), Mar del Plata, Argentina, 15-19 November 1998.

16. Food and Agriculture Organization of the United Nations (FAO). Sustainability Assessment of Food and Agriculture Systems: SAFA Guidelines, Version 3.0; Food and Agriculture Organization of the United Nations: Rome, Italy, 2013; Available online: http:/ / www.fao.org/fileadmin/templates/nr/sustainability_pathways/docs/SAFA_Guidelines_Version_3.0 (accessed on 5 December 2020).

17. Häni, F.; Braga, F.; Stämpfli, A.; Keller, T.; Fischer, M.; Porsche, H. RISE, a tool for holistic sustainability assessment at the farm level. IAMA Int. Food Agribus. Manag. Rev. 2003, 6, 78-90.

18. IISD. Seeking Sustainability —COSA Preliminary Analysis of Sustainability Initiatives in the Coffee Sector; International Institute for Sustainable Development: Winnipeg, MB, Canada, 2008.

19. Gasso, V. Assessing Sustainability of Agricultural Systems: Balancing Context Specificity and Generality. Ph.D. Thesis, Aarhus University, Aarhus, Denmark, 2014

20. Gasso, V.; Oudshoorn, F.W.; De Olde, E.; Sørensen, C.A.G. Generic sustainability assessment themes and the role of context: The case of Danish maize for German Biogas. Ecol. Indic. 2014, 49, 143-153. [CrossRef]

21. Al Shamsi, K.; Compagnoni, A.; Timpanaro, G.; Cosentino, S.L.; Guarnaccia, P. A Sustainable Organic Production Model for "Food Sovereignty" in the United Arab Emirates and Sicily-Italy. Sustainability 2018, 10, 620. [CrossRef]

22. Borlaug, N.E. The Green Revolution: For bread and peace. Bull. Atom. Sci. 1971, 27, 6-48. [CrossRef]

23. Wezel, A.; Bellon, S.; Doré, T.; Francis, C.; Vallod, D.; David, C. Agroecology as a science, a movement and a practice. Agron. Sustain. Dev. 2009, 29, 503-515. [CrossRef]

24. Altieri, M.A. Agroecology: A new research and development paradigm for world agriculture. Agric. Ecosyst. Environ. 1989, 27, 37-46. [CrossRef]

25. Levidow, L.; Pimbert, M.; Vanloqueren, G. Agroecological research: Conforming-or transforming the dominant agro-food regime? Agroecol. Sustain. Food Syst. 2014, 38, 1127-1155. [CrossRef]

26. Alliance for Food Sovereignty in Africa (AFSA). Agroecology: The Bold Future of Farming in Africa; AFSA and Tanzania Organic Agriculture Movement: Dar es Salaam, Tanzania, 2016.

27. Hatt, S.; Artu, S.; Bredart, D.; Lassois, L.; Francis, F.; Haubruge, E.; Garre, S.; Stassart, P.M.; Dufrene, M.; Monty, A.; et al. Towards sustainable food systems: The concept of agroecology and how it questions current research practices. A review. Biotechnol. Agron. Soc. Environ. 2016, 20, 215-224.

28. Food and Agriculture Organization of the United Nations (FAO). Agroecology Knowledge Hub. Available online: http: / /www.fao.org/agroecology/overview/en/ (accessed on 2 December 2020).

29. Timpanaro, G.; Bellia, C.; Foti, V.T. Horticultural agro-biodiversity and potential conser-vation: Case study in Sicily. Qual. Access Success 2014, 15, 230-235.

30. Wezel, A.; Casagrande, M.; Celette, F.; Vian, J.F.; Ferrer, A.; Peigné, J. Agroecological practices for sustainable agriculture. A review. Agron. Sustain. Dev. 2014, 34, 1-20. [CrossRef]

31. Wiget, M.; Muller, A.; Hilbeck, A. Main challenges and key features of indicator-based agroecological assessment frameworks in the context of international cooperation. Ecol. Soc. 2020, 25, 25. [CrossRef]

32. Purvis, M.; Smith, R. Sustainable agriculture for the 21st century. In Exploring Sustainable Development: Geographical Perspectives; Purvis, M., Grainger, A., Eds.; Routledge: Abingdon, UK, 2004; pp. 179-206.

33. Slatmo, E.; Fischer, K.; Roos, E. The Framing of Sustainability in Sustainability Assessment Frameworks for Agriculture. Sociol. Rural. 2017, 57, 378-395. [CrossRef]

34. Andrighetto, I.; Berzaghi, P.; Cozzi, G. Dairy feeding and milk quality: The extensive systems. Zoot. Nutr. Anim. 1996, 22, 241-250.

35. Porqueddu, C. Low-input farming systems in Southern Europe: The role of grasslands for sustainable livestock production. In Proceedings of the Joint Research Centre Summer University, Ranco, Ispra, 2-5 July 2007; pp. 52-58.

36. Sinab. "BIO IN CIFRE 2020": I Dati Nazionali sul Biologico. 2020. Available online: http://www.sinab.it/bionovita/bio-cifre-20 20-i-dati-nazionali-sul-biologico (accessed on 13 December 2020).

37. Sturiale, L.; Scuderi, A.; Timpanaro, G.; Matarazzo, B. Sustainable Use and Conservation of the Environmental Resources of the Etna Park (UNESCO Heritage): Evaluation Model Supporting Sustainable Local Development Strategies. Sustainability 2020, 12, 1453. [CrossRef] 
38. Cozzi, G.; Bizzotto, M.; Rigoni Stern, G. Uso del territorio, impatto ambientale, benessere degli animali e sostenibilità economica dei sistemi di allevamento della vacca da latte presenti in montagna. Il caso studio dell'Altipiano di Asiago. Quad. SOZOOALP 2006, 3, 7-25.

39. Kleijn, D.; Kohler, F.; Báldi, A.; Batáry, P.; Concepción, E.D.; Clough, Y.; Díaz, M.; Gabriel, D.; Holzschuh, A.; Knop, E.; et al. On the relationship between farmland biodiversity and landuse intensity in Europe. Proc. R. Soc. B Biol. Sci. 2009, 276, 903-909. [CrossRef] [PubMed]

40. Nagendra, H.; Reyers, B.; Lavorel, S. Impacts of land change on biodiversity: Making the link to ecosystem services. Curr. Opin. Environ. Sustain. 2013, 5, 503-508. [CrossRef]

41. Mirazo-Ruiz, J. Environmental benefits of extensive livestock farming: Wildfire prevention and beyond. In Economic, Social and Environmental Sustainability in Sheep and Goat Production Systems; Bernués, A., Boutonnet, J.P., Casasús, I., Chentouf, M., Gabiña, D., Joy, M., López-Francos, A., Morand-Fehr, P., Pacheco, F., Eds.; CIHEAM/FAO/CITA-DGA Publ.: Zaragoza, Spain, 2011; pp. $75-82$.

42. Nemecek, T. Environmental impacts of Swiss milk production in the mountain region. In Grassland Farming and Land Management Systems in Mountainous Regions; Pötsch, E.M., Krautzer, B., Hopkins, A., Eds.; European Grassland Federation Publ.: Zurich, Switzerland, 2011; pp. 305-307.

43. Riedel, J.L.; Casasús, I.; Bernués, A. Sheep farming intensification and utilization of natural resources in a Mediterranean pastoral agro-ecosystem. Livest. Sci. 2007, 111, 153-163. [CrossRef]

44. ISTAT. $6^{\circ}$ Censimento Generale dell'Agricoltura in Sicilia Risultati Definitivi. 2012. Available online: https://www.istat.it/it/ archivio/76410 (accessed on 3 December 2020).

45. Bernués, A.; Ruiz, R.; Olaizola, A.; Villalba, D.; Casasús, I. Sustainability of pasture-based livestock farming systems in the European Mediterranean context: Synergies and trade-offs. Livest. Sci. 2011, 139, 44-57. [CrossRef]

46. Foti, V.T.; Scuderi, A.; Stella, G.; Timpanaro, G. Consumer purchasing behaviour for "biodiversity-friendly" vegetable products: Increasing importance of informal relationships. Agric. Econ. 2019, 65, 404-414. [CrossRef]

47. De Olde, E.M.; Oudshoorn, F.W.; Sørensen, C.A.; Bokkers, E.A.; De Boer, I.J. Assessing sustainability at farm-level: Lessons learned from a comparison of tools in practice. Ecol. Indic. 2016, 66, 391-404. [CrossRef]

48. De Olde, E.M.; Sautier, M.; Whitehead, J. Comprehensiveness or implementation: Challenges in translating farm-level sustainability assessments into action for sustainable development. Ecol. Indic. 2018, 85, 1107-1112. [CrossRef]

49. Gayatri, S.; Gasso-tortajada, V.; Vaarst, M. Assessing Sustainability of Smallholder Beef Cattle Farming in Indonesia: A Case Study Using the FAO SAFA Framework. J. Sustain. Dev. 2016, 9, 3. [CrossRef]

50. Soldi, A.; Aparicio Meza, M.J.; Guareschi, M.; Donati, M.; Insfrán Ortiz, A. Sustainability Assessment of Agricultural Systems in Paraguay: A Comparative Study Using FAO's SAFA Framework. Sustainability 2019, 11, 3745. [CrossRef]

51. Free and Open Access SAFA Tool 2.2.4.0. Available online: http://www.fao.org/nr/sustainability/sustainability-assessmentssafa/safa-tool/it/ (accessed on 5 September 2020).

52. Heffernan, O. Sustainability: A meaty issue. Nature 2017, 544, S18-S20. [CrossRef]

53. Halland, H.; Bertella, G.; Kvalvik, I. Sustainable value: The perspective of horticultural producers in Arctic Norway. Int. Food Agribus. Manag. Rev. 2020, 24, 51-70. [CrossRef]

54. Schader, C.; Curran, M.; Heidenreich, A.; Landert, J.; Blockeel, J.; Baumgart, L.; Ssebunya, B.; Moakes, S.; Marton, S.; Lazzarini, G.; et al. Accounting for uncertainty in multi-criteria sustainability assessments at the farm level: Improving the robustness of the SMART-Farm tool. Ecol. Indic. 2019, 106, 105503. [CrossRef]

55. Schader, C.; Baumgart, L.; Landert, J.; Muller, A.; Ssebunya, B.; Blockeel, J.; Weisshaidinger, R.; Petrasek, R.; Mészáros, D.; Padel, S.; et al. Using the Sustainability Monitoring and Assessment Routine (SMART) for the systematic analysis of trade-offs and synergies between sustainability dimensions and themes at farm level. Sustainability 2016, 8, 274. [CrossRef]

56. Yunlong, C.; Smit, B. Sustainability in agriculture: A general review. Agric. Ecosyst. Environ. 1994, 49, 299-307. [CrossRef]

57. Farm to Fork Strategy: For a Fair, Healthy and Environmentally-Friendly Food System. Available online: https://ec.europa.eu/ food/sites/food/files/safety/docs/f2f_action-plan_2020_strategy-info_en.pdf (accessed on 12 December 2020).

58. Scuderi, A.; Foti, V.; Timpanaro, G. The Supply Chain Value of POD and PGI Food Products through the Application of Blockchain. Calitatea 2019, 20, 580-587. 